\title{
Editorial
}

\section{El humanismo en enfermería a través de la sociopoética y la antropoética}

\author{
José Siles González \\ Catedrático E.U. Facultad de Ciencias de la Salud. Universidad de Alicante
}

Cómo citar esta editorial en edición digital: Siles González, J. (2014) El humanismo en enfermería a través de la sociopoética y la antropoética. Cultura de los Cuidados (Edición digital) 18, 38. Disponible en: http://dx.doi.org/10.7184/cuid.2014.38.01>

Correspondencia: Departamento de enfermería. Universidad de Alicante. 03080 Alicante.

Correo electrónico: jose.siles@ua.es

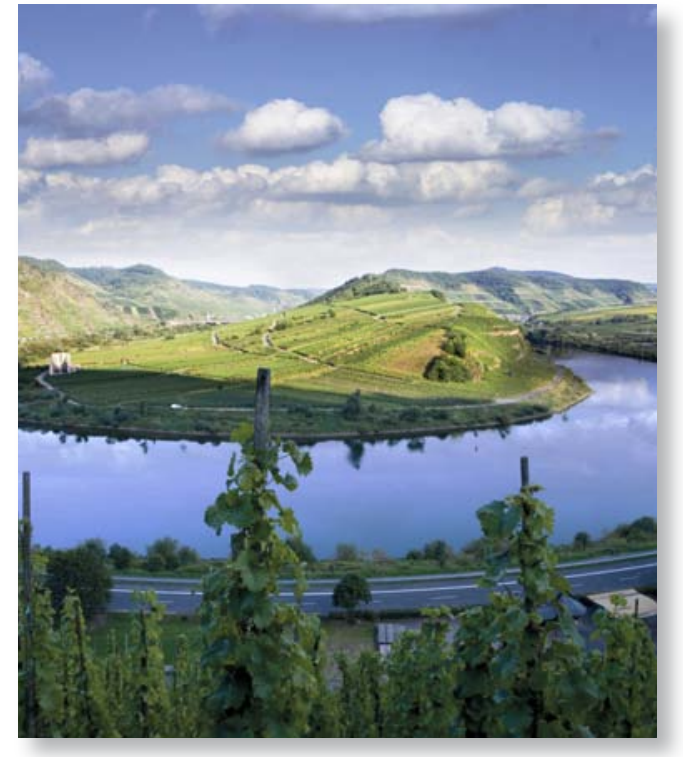

La presente editorial surge ante la necesidad de explicar una nueva iniciativa: la potenciación de la sociopoética y la antropología narrativa en Cultura de los Cuidados. A partir del presente número, Cultura de los Cuidados va a introducir en la sección fenomenología dos subsecciones dedicadas a la sociopoética y a la antropología narrativa. Poemas en los que se expresen los sentimientos, creencias y valores que emergen del océano intersubjetivo en el que navegan los cuidados; narraciones en las que se relaten hechos, circunstancias, creencias y sentimientos implicados en situaciones de vida-salud-enfermedad; tendrán cabida a partir de ahora en esta revista que cumple 18 años de existenciay que ha contribuido, por supuesto desde la modestia de su limitada e imperfecta realidad, a la integración de la narrativa mediante los relatos publicados en la sección de fenomenología y en las diversas ediciones del premio "Vida y Salud de Narrativa”, decano entre los de su género. De alguna forma, la sociopoética y la antropología narrativa constituyen instrumentos de comunicación (que van más allá del mero intercambio de información o conocimiento) que tienen que ser aprovechados por todos: profesionales de la educación y de la salud, educandos y, por supuesto, pacientes. Todos ellos pueden y deben activar su voz para participar en la gestión de sus procesos educativos y de salud. Es por ello que, independientemente de las actuales tendencias que inciden en el diseño, el contenido e incluso la filosofía de las publicaciones científicas: indizaciones que transforman a las revistas en herramientas casi exclusivas para valorar la actividad investigadora de los autores, mercantilismo editorial, etcétera; Cultura de los Cuidados, retomando el ideario de su génesis, va seguir apostando fuerte por el humanismo en ciencias de la salud mediante la potenciación de dos instrumentos pertinentes 
para el cumplimiento de dicho objetivo: la sociopoética y la antropología narrativa.

\section{La complejidad de la sociopoética y la inter- subjetividad en el contexto de la enfermería.}

La sociopoética puede entenderse como un método de investigación que estudia las formas de expresión que, a través de los sentidos, provocan en las personas situaciones de intersubjetividad en procesos de enseñanza aprendizaje, cuidados de salud, relaciones familiares, sociales, laborales, etc. Para algunos autores, la sociopética ha sido considerada como un puente entre la ciencia y el arte. Para la mayoría de los investigadores, la sociopoética potencia facetas muy específicas y no demasiado trabajadas para la mayoría de los seres humanos: la creatividad, la intuición y la sensibilidad (Paiva Moraes, Batista Braga, Carneiro Sileveria, 2003)

Uno de los grandes problemas de conceptos como el de "sociopoética" es su carácter de encrucijada o cruce transdisciplinar, dado que resulta extremadamente complicado definirla dada su naturaleza compleja constituida por una madeja de interrelaciones liminares casi irreductibles a lo que se entiende por "definición". En ese sentido nos encontramos con autores que hablan de sociopoética desde la fenomenología sociológica y la intersubjetividad, proponiendo a Max Weber, Alfred Schütz y el interaccionismo simbólico de la Escuela de Chicago, como antecedentes de la sociopoética desde el contexto de la acción social (Chocarro González, 2913), aunque también hay que considerar la pedagogía del oprimido de Freire como un referente esencial de los estudios sociopoéticos (Freire, 1987). Sin embargo, la sociopoética también puede y debe ser abordada desde la óptica de la estética de los cuidados y contribuir al engrosamiento del patrón esté- tico de la enfermería. Otra dificultad añadida es la aparente dicotomía entre la expresión del sentimiento puro monopolizado por la poesía (estética), y otras formas de intersubjetividad de tipo narrativo donde también caben expresiones poéticas $\mathrm{o}$, dicho de otro modo, donde el relato permite la expresión de emociones que emanan de la descripción de momentos intersubjetivos o de la mera subjetividad (Siles y Solano, 2011).

En definitiva: sociopoética, antropología narrativa, fenomenología, intersubjetividad, interaccionismo simbólico y estética; constituyen enfoques disciplinares y metodológicos que pueden ser muy útiles en un campo tan amplio y complejo como es el de la interacción entre personas que ejercen diferentes roles (paciente-profesional) en situaciones de salud enfermedad. Siguiendo a Cody (1995) la enfermería y la educación son terrenos abonados para las experiencias intersubjetivas en las que florecen los sentimientos, las emociones $y$ todo tipo de inquietudes e incertidumbres.

\section{Paradigmas, sociopoética y estética de los cuidados.}

La sociopoética resulta coherente y pertinente metodológicamente con los principios del paradigma hermenéutico, puesto que facilita la comprensión de los actos intersubjetivos entre paciente y profesional, pero la sociopoética rebasa los límites del paradigma interpretativo, dado que integra al paciente o discente en el proceso intersubjetivo como un coinvestigador; es decir, lo considera un participante activo del proceso de investigación dado que lo dota de voz (Siles, 2010), lo cual implica transitar por los parámetros establecidos en el paradigma sociocrítico en cuyos presupuestos, la pasividad del discente o del paciente no tienen cabida. En ese mismo sentido, la so- 
ciopoética y la antropología narrativa, tras la comprensión y extracción de significado de las situaciones de cuidados o educativas, contribuyen a la rentabilización de las experiencias y conocimientos del paciente en el proceso de sus propios cuidados (autocuidados) y, asimismo, facilitan la concienciación del paciente o educando (empoderamiento compartido con el profesional) como sujeto relevante en la planificación y dispensación de sus cuidados y/o educación (Siles, 1997). Asimismo, la sociopoética contribuye a la práctica de los principios del paradigma sociocrítico en la medida en que postula la producción colectiva del conocimiento por parte de los investigadores y los sujetos investigados, facilitando el holismo en el proceso de investigación en el que no se adopta el reduccionismo metodológico habitual en el contexto neopositivista y se mantiene, por el contrario, la globalidad atendiendo a las dimensiones: intelectual, sensible, emocional, intuitiva, teórica, práctica y sensoromotora (Fleuri, et al: 2004)

Para identificar la eficacia de la sociopoética en temas que transcienden el plano individual y van más allá, a la socialización de la sanidad y la educación; podríamos establecer cierto paralelismo entre la pedagogía del oprimido de Freire y la atención de salud recibida por pacientes enquistados en deletéreos nirvanas en los que impera la pasividad, la dependencia y una obediencia casi ciega en la autoridad de los profesionales sanitarios; se trata de una situación en la que campa el despotismo ilustrado en pleno siglo XXI: todo para el paciente, pero sin el paciente. La superación de esta situación a la que se ha llegado tras siglos de adoctrinamiento desde la perspectiva de sociedades "profesionalizadas" (adaptadas al interés de tal o cual actividad profesional) pasa por la concienciación de la ciudadanía respec- to a su responsabilidad en materia educativa y de salud. En esta situación de concienciación, el educando o el paciente se erigen en sujetos de la acción en la que interactúan con profesionales sin que se empleen mecanismos de dependencia o sumisión avala la idoneidad del paradigma sociocrítico para socavar la tradición imperante de culturas dominantes (profesionales) y dominadas (educandos, pacientes) características de las sociedades "medicalizadas" o "pedagogizadas".

Es en este sentido de instrumento facilitador de la concienciación del humanismo en cuidados y educación, en el que la sociopoética adquiere una especial relevancia. Los conceptos educación y los cuidados comparten un significado que implica la dimensión afectiva en la medida en la que las interacciones sociales que se producen en los procesos educativos y de cuidados provocan un cruce de sentimientos que constituyen la materia prima de la dimensión afectiva. Gautier, en esta misma línea, acuñó un neologismo "confetos" para tratar de sintetizar la relación entre la dimensión conceptual y la afectiva en el contexto de las culturas dominadas (cultura del cliente con respecto a la del profesional). Las expresiones desarrolladas por las culturas resistentes facilitan el desahogo emocional por sí mismas, pero, además, contribuyen a la construcción de sentimientos y conocimientos colectivos: concienciación de la realidad de la cultura dominada, estrategias de resistencia y drenaje emocional, herramienta de comunicación e interacción con la cultura dominante (profesionales), etc.

La estética de los cuidados puede ser válida para el desarrollo de la sociopoética y el aprovechamiento de situaciones de intersubjetividad en el contexto educativo y de enfermería. Etimológicamente, la palabra estética deriva 
del griego (aisthetikê) "sensación, percepción" y de (aisthesis) “sensación, sensibilidad". Siles y Solano (2011) sostienen que la estética puede interpretarse como la ciencia que estudia e investiga el origen sistemático del sentimiento puro y su manifestación, que es el arte, según afirma Kant en su "Crítica del juicio". En este sentido, la sociopoética está estrechamente vinculada con la estética en tanto facilita la comunicación de los sentimientos en el transcurso de la práctica del arte de los cuidados.

\section{Relación de la sociopoética con la antropoé-} tica.

En la vinculación entre sociopoética y antropoética es donde se pone de manifiesto la gran importancia que tiene la clarificación paradigmática del conjunto de actividades realizadas por investigadores, educadores y cuidadores. El paradigma sociocrítico, al integrar en los procesos de investigación de fenómenos educativos o de cuidados a los sujetos investigados, los educandos o los pacientes; se trasforma en un modelo ético en el que el humanismo constituye un referente esencial de primer orden. Este enfoque participativo de la educación, la enfermería y, por supuesto, otras disciplinas sigue las orientaciones de la pedagogía del oprimido de Freire en la que el educando o el paciente no son manipulados para ejercer un rol de exclusiva pasividad y dependencia del profesional; pero, sobre todo, adopta los parámetros de humanismo ético aportado por Morin en su antropoética. En la antropoética de Morin, lo fundamental en cualquier tipo de relación entre personas es la explicitación del humanismo que todas comparten de forma tácita, de manera que este humanismo incide en la forma de desarrollar las relaciones humanas en general y la intersubjetividad entre educandos y educadores o pacientes y profesionales de la salud en particular, dado que tal como afirma Morin la antropoética debe entenderse como: "una ética del bucle de los tres términos individuo-sociedad-especie, pues es de donde emerge la conciencia y nuestro espíritu propiamente humano, es una conciencia de la individualidad compleja más allá de la individualidad, que conlleva la esperanza de comprender la humanidad, para lograr la humanidad del sujeto" (Morin, 1999). Antropoética viene a significar "hombre ético", es decir un hombre con obligaciones morales para con él, sus semejantes y la naturaleza. En definitiva, una manera organizada de sentir y vivir la vida que rima en asonante y en consonante con el concepto más generoso de humanismo. En esta misma línea, Morín (1999) sostiene que hay 7 saberes necesarios que se deben aplicar en la educación del futuro en cualquier sociedad y que son los siguientes:

Las cegueras del conocimiento: el error y la ilusión.

Los principios de un conocimiento pertinente.

- Enseñar la condición humana.

- Enseñar la identidad terrenal.

- Enfrentar las incertidumbres.

- Enseñar la comprensión.

- La ética del género humano.

\section{Sociopoética y antropología narrativa}

No sólo la sociopoética contribuye a este proceso de clarificación y rentabilización pedagógica de la intersubjetividad, la antropología narrativa, mediante el estudio de los relatos en los que se describen de forma holística y narrativa situaciones o hechos, creencias, valores y sentimientos implicados en las intersubjetividades que acontecen durante la implementación de los procesos de enseñanza aprendizaje y cuidados de salud; comparte esa dimensión 
pedagógica de la intersubjetividad. La antropología narrativa, por tanto, permite conocer, comprender, analizar y reflexionar sobre las experiencias relacionales acontecidas en los procesos educativos, de cuidados, sociales y laborales sin renunciar a los elementos menos visibles o evidentes de los mismos: creencias, valores y sentimientos (Siles, Ed. 2000).

En definitiva y para hacer realidad, poco a poco esta propuesta, hacemos un llamamiento a todos aquellos profesores, alumnos, profesionales de la salud, pacientes y a poetas y narradores, interesados en dar a conocer temáticas relacionadas con todos los aspectos y circunstancias que tengan que ver con el variadísimo intervalo comprendido entre las situaciones de salud-enfermedad.

\section{Bibliografía}

- Alvarado Hernández, V.M. Manjarrez Betancour, M. (2009) La conformación de la antropoética a través de la tutoría académica en educación superior. (el caso del posgrado). Revista Educación 33(1): 167-176.

- Chocarro González, L. (2013) La intersubjetividad y su relevancia en los cuidados de Enfermería. Index de Enfermería [Index Enferm] (edición digital). 22(4). Disponible en http://www.index-f.com/index-enfermeria/ v22n4/9244.php

- Cody W. (1995) Intersubjectivity: Nursing's contribution to the explication of its postmodern meaning. Nursing Science Quarterly. 8(2): 52-54.

- Díaz Agea, J.L. (2008) El sufrimiento medicalizado. 2(23): 50-56.

- Fleuri R., Prefácio. I.N., Santos, I., Gauthier, J., Figueiredo, N.M.A., Petit S.H. (2004) Práctica de investigación en Ciencias Humanas y Sociales - Abordaje Sociopoético. Atheneu, 2.

- Freire, P. (1987) Pedagogía del Oprimido. Paz e Terra, Río de Janeiro.

- Santos, I., Gauthier, J. (1999) Enfermagem-Análise Institucional e Sociopoética.: Ed. Anna Nery / UFRJ, Rio de Janeiro.
- Gauthier J. (1999) Sociopoética-encontro entre arte, ciência e democracia na pesquisa em ciências humana e social, enfermagem e educação. Ed. Anna Nery / UFRJ, Río de Janeiro.

- Illich, I. (2004) La sociedad desescolarizada. FCE, México D.F..

- Morin, E. (2005) Introducción al pensamiento complejo. Gedisa, Barcelona.

- Morín, Edgar (1999) Los siete saberes necesarios para la educación del futuro. Correo de la UNESCO, París, Francia.

- Paiva Moraes, L.M., Batista Braga, V.A., Carneiro Sileveria, L. (2003) Socipoética e enfermagem: una aproximación en la investigación con adolescentes Revista Baiana da Enfermagem.18:89-96

- Santos, I. (2005) Sociopoética: un puente para "cuidar investigar” en enfermería Index Enferm14 (50): 35-37. http://dx.doi.org/10.4321/S1132-12962005000200007

- Siles J. (1997) Epistemología y enfermería: por una fundamentación científica y profesional de la disciplina. Enfermería Clínica, 7/4: 188-194.

- Siles González, J. (2010) Historia cultural de enfermería: reflexión epistemológica y metodológica. Av. enferm 28:120-128

- Siles, J. y Solano, C. (2011). Cultural history and aesthetics of nursing care. Rev. Latino-Am. Enfermagem, 5, 1096-1105. Available

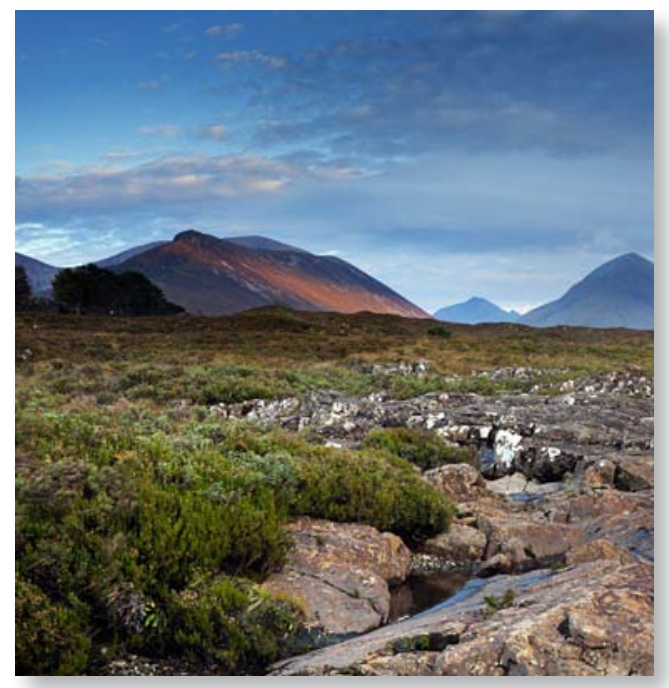

